\title{
Promoción digital para potenciar el turismo en la comuna data de Posorja, Ecuador.
}

\section{Digital promotion to boost tourism in the commune dates from Posorja, Ecuador.}

Samuel Ricardo Guillén Herrera. ${ }^{1}$, Lissette Estefanía Quinde Torres. ${ }^{2}$, Víctor Manuel Vera Peña. ${ }^{3} \&$ Lila Pilar Hasing Sanchez. ${ }^{4}$

\section{Resumen.}

El presente trabajo de investigación tiene como objetivo proponer el diseño de un plan de promoción digital para potenciar el turismo en la Comuna Data de Posorja porque existe poca afluencia de visitantes, especialmente en días no feriados. A través de técnicas de investigación de enfoque mixto, se determinó el posible perfil de la demanda, las estrategias que se utilizarán y los medios, dando como resultado las redes sociales facebook e instagram. El problema recae en el desconocimiento de los atractivos turísticos de este destino como consecuencia de la escasa información disponible en canales de difusión usados actualmente. Implementando la propuesta de este proyecto, que incluye el diseño de un imagotipo como marca turística, se logrará el posicionamiento de este sitio virgen y con un gran legado cultural como uno de los más visitados de la provincia del Guayas.

Palabras claves: Plan de promoción digital, Comuna Data de Posorja, redes sociales, promoción, digital, estrategias de difusión, oferta turística.

\section{Abstract.}

The objective of this research work is to propose the design of a digital promotion plan to boost the tourism in the Commune Data of Posorja because there is little influx of

\footnotetext{
${ }^{1}$ Universidad de Guayaquil, Ecuador. samuel.guillenh@ug.edu.ec

${ }^{2}$ Universidad de Guayaquil, Ecuador. lissette-05@live.com

${ }^{3}$ Universidad de Guayaquil, Ecuador victor.verap@ug.edu.ec

${ }^{4}$ Universidad de Guayaquil, Ecuador lila.hasings@ug.edu.ec
} 
visitors, especially on non-holiday days. Through the mixed approach research techniques, the possible profile of the demand, the strategies that will be used and the means resulting in the facebook and instagram social networks were determined. The problem lies in the ignorance of the tourist attractions of this destination as a result of the scarce information available in broadcast channels currently used; Implementing the proposal of this project, which includes the design of an imagotype as a tourist brand, will achieve the positioning of this virgin site and with a great cultural legacy as one of the most visited in the Province of Guayas.

Keywords: Digital promotion plan, Comuna Data de Posorja, social networks, promotion, digital, dissemination strategies, tourist offer.

\section{Introducción.}

Ecuador es un país que posee una amplia riqueza tanto natural como cultural, por esta razón es conocido en el mundo como un destino con una enorme biodiversidad a pesar de ser geográficamente pequeño; esta diversidad empieza al poseer 4 regiones o 4 mundos en un sólo país, existe variedad tanto en flora, fauna, costumbres, creencias, nacionalidades, gastronomía, lengua, clima, entre otros aspectos., pero desafortunadamente no todos sus atractivos cuentan con mucha demanda por el motivo de que son desconocidos para la mayoría de personas.

La Provincia del Guayas recoge una variedad de recursos turísticos, tales como playas, parques recreacionales, áreas protegidas, ríos, producción agrícola, diversas líneas de turismo, y riqueza de flora y fauna. Políticamente está dividida en 25 cantones, de los cuales destaca Guayaquil, conocido como la Perla del Pacífico. Este cantón a su vez se divide en parroquias que no tienen un mismo desarrollo a nivel turístico y cuyos atractivos no son tan conocidos ni promocionados por los entes encargados de esta área. Es el caso de la Comuna Data de Posorja pertenece a la parroquia rural Posorja del cantón Guayaquil, cuenta con atractivos turísticos que poseen un gran valor cultural pero aún se la puede definir como un destino escondido o desconocido por muchos turistas. Esto se debe a la insuficiente información disponible en los diversos medios de comunicación y difusión que están al alcance de la mayoría de las personas, es decir que, la información que circula en los medios digitales

Al existir una limitada información de los recursos turísticos que posee la Comuna Data de Posorja se da origen a una insuficiente demanda de visitantes cuyo resultado consiste en bajos ingresos económicos para los habitantes de este destino. A pesar de poseer recursos natrales y culturales que fascinan a quienes visitan este destino, los mismos tienen un significado para sus habitantes como por ejemplo, la escultura gigante El Delfín representa la llegada de esta especie a las orillas de la playa. Al dar a conocer a la comuna como un sitio turístico con diversas alternativas que generen interés en las personas, se beneficiaría directamente a los comuneros. Su economía está basada en actividades como la pesca, agricultura de plantaciones de ciclo corto y el turismo, ellos esperan obtener una mayor acogida de parte de los turistas, es decir que su número de visitas aumente, y de esta forma incrementar sus ingresos y mejorar su calidad de vida. 
La situación expuesta anteriormente llevó al investigador a Proponer el diseño de un plan de promoción digital para potenciar el turismo de la Comuna Data de Posorja. Y para lograrlo se Revisó documentos que permitieron el fundamento de la propuesta Se delimitó el nicho de la demanda, su perfil, gustos, preferencias y hábitos digitales para de esta manera diseñar una Oferta turística que vaya acorde al plan de promoción digital de la Comuna Data de Posorja para incrementar el número de llegada de turistas a este destino.

Este plan de promoción digital diseñado para la Comuna Data de Posorja a los recursos turísticos que posee, aumentará la afluencia de turistas como resultado de la información disponible sobre este destino en los medios de comunicación más utilizados en la actualidad, especialmente a través de los dispositivos digitales que traen consigo la inmediatez y permiten llegar a un mayor público en el cual se generarán expectativas e interés, se interactuará con ellos respondiendo a sus inquietudes y una vez que se decidan por visitar a la comuna se les brindará un servicio de calidad generando gratas experiencias esperadas a ser compartidas en sus diversas redes sociales.

\section{Métodos}

Para la presente investigación se utilizó en primera instancia la revisión bibliográfica fundamentando teóricamente conceptualizaciones, teorías, y nuevas tendencias del marketing digital aplicado al turismo comunitario. Se utilizó también la entrevista para determinar los antecedentes de promoción, estrategias aplicadas actualmente, líneas de turismo, atractivos turísticos, promoción digital, entre otros aspectos del destino, las mismas fueron realizadas a los líderes de la Comuna, y para conocer sobre las nuevas tendencias en cuanto al Marketing digital se entrevistó a expertos en el área.

En su segunda fase se realizó la observación participativa in situ, para realizar un levantamiento de información acerca del estado de los recursos y servicios turísticos y por ultimo de acuerdo a los indicadores proyectados de las técnicas utilizadas en las fases anteriores se realizó una encuesta, la misma que fue aplicada a turistas que conocen la Comuna Data de Posorja para referenciar su perfil digital de forma general y la percepción acerca del destino mediante preguntas cerradas categorizadas en forma de escala y de opción múltiple que permitieron obtener información más precisa y de fácil entendimiento. Esto permitió al investigador plantear su propuesta del Plan de Marketing Digital para la Comuna Data Posorja del Cantón Guayaquil de la Provincia del Guayas

\section{Resultados}

En los resultados obtenidos se pudo establecer que en la actualidad se han realizado investigaciones con temas de promoción digital, su relación radica en que el término promoción es un componente del marketing Mix 4P's.[1] De ahí que en la actualidad los destinos están acaparando la atención de su demanda mediante acciones promocionales con el uso de recursos digitales, como computadores, teléfonos, tabletas, consolas, sitios webs, e-mail, apps y redes sociales, así como también mediante TV, radio, SMS y canales de difusión online como banners y flyers, [2], que promueven la visita a estos sitios permitiendo la interacción entres turistas, residentes y entes gobernantes turísticos. [3] 
En la actualidad época en el que el conocimiento tiene mayor valoración en los sistemas económicos, donde las literaturas hablan del volumen y velocidad del conocimiento, que casi pareciera suficiente conectarse a internet para impulsar el desarrollo socioeconómico [4 ] . Es la era de la Big Data, el análisis de datos masivos en el que nuestra información demográfica está registrada en medios digitales, así como nuestros gustos y preferencias lo que nos hace ser fácilmente segmentados por parte de las empresas que utilizan la promoción digital para vendernos sus productos [ 5 ]. En el turismo está siendo parte de esta tendencia y los destinos que están usando estrategias de promociones digitales ya tienen resultados óptimos [ 6 ].

Como en Portugal en el que los Municipios al dase cuenta que la comercialización de sus productos, destinos y servicios turísticos se han visto influenciados notablemente por las nuevas tendencias en las TICs, que cubren una estructura informativa que cubre toda la información de la ciudad con atributos, valores, e impactos visuales que crea la imagen de la ciudad, siendo la imagen de destino cultural que más se evidencia en los municipios de Portugal, producto de la promoción digital que se ha dado a este tipo de turismo, para dejar de un lado al tradicional turismo de sol y playa, consolidando la identidad cultural de los municipios y creando conciencia a sus habitantes a valorar el patrimonio que poseen en sus ciudades. [7]

Por otro lado, tenemos a Comunitat Valenciana que basó su Plan de Marketing Turístico 2012 en el Plan Estratégico de Turismo de la Comunitat Valenciana 2010-2020 que entre otros aspectos busca la aplicación de las nuevas tecnologías para crear un destino competitivo que permita la diferenciación con otros sitios. Como fundamento de este estudio se tomó en cuenta la opinión de representantes de empresas turísticas; también, se determinó el "escenario turístico" de este destino en el cual se revisaron estadísticas correspondientes a llegadas de turistas, se elaboró un perfil de demanda y se elaboraron predicciones para sus diferentes mercados,[8] Utilizando estrategias como

- Campaña de video marketing del destino Comunitat Valenciana a través de branded channel en YouTube.

- Campaña social media marketing (SMM) a través de acciones en las principales redes sociales como Facebook, Twitter, Flickr, Youtube, Tuenti, etc. Tanto en mercado nacional como en los principales mercados extranjeros, que buscarán especialmente la viralización y generación de contenido por los usuarios.

- Google Adwords en mercados prioritarios: Reino Unido, Alemania y Francia.

- Desarrollo de apps y advergamings para generar notoriedad y fidelizar al cliente.

- Campaña de display y de email marketing en medios online de viajes (OTAs y comunidades de viajeros).

En Valledupar, Colombia, se desarrollaron estrategias de promoción digital para posicionar su Marca Ciudad, para promoverla como un destino turístico, centro de negocios y lugar de residencia, mediante una aplicación que va más allá de mostrar contenido bonito de la ciudad, se trata de una oficina de promoción turística virtual que ofrece información que necesita sobre qué ver, dónde pernoctar, qué comer, qué comprar; 
actividades de ocio, eventos, servicios, mapa con los puntos de interés geolocalizados, para llevar al usuario hasta ellos, y la historia de la ciudad. Estas estrategias son consideradas guías que pueden ser aplicadas en otros destinos, recalcando que el hecho de no usar papeles para afiches protege el medio ambiente. [9]

Ya enfocándose en estudios realizados en el Ecuador, tenemos al cantón Caluma de la provincia de Bolívar, aquí se realizó el diseño de un sistema de gestión de Marketing Digital con el fin de desarrollar el turismo en este cantón que cuenta con las modalidades de ecoturismo y turismo de naturaleza. Los medios digitales utilizados fueron sintetizados en un cuadro teniendo como marca a Caluma turístico en los diversos medios. [10] A través de estrategias definidas como resultado al estudio del mercado y tomando en cuenta sus necesidades se ha incrementado el número de visitas y se ha logrado que los turistas hagan uso de las diferentes instalaciones y servicios que posee el destino Caluma, tales como alimentación, hospedaje y transporte; se ha logrado un equilibrio entre desarrollo socioeconómico y turismo sostenible.

Otro ejemplo a citar lo encontramos en el cantón Penipe Provincia del Chimborazo que mediante la web 3.0 se realizaron fotografías, videos y tours virtuales que responden a una estrategia digital efectiva aplicada al turismo, este tipo de herramientas favoreció a la interacción de los usuarios digitales y aumentar la demanda turística a este sitio [11]

Las estrategias de promoción que tiene entre sus fines destacados el posicionamiento de una marca, aumentar las ventas, o el lanzamiento de nuevos productos, y el uso digital con aplicaciones de geolocalización y realidad virtual para este fin es cada vez más frecuente [12]. Las formas en como circula esta información es una preocupación para el Estado, que cada vez busca mejores formas de regular el contenido, sin lograrlo plenamente aún [13]. La promoción digital tiene entre sus tendencias en el uso que le pueden dar los destinos turísticos varios aspectos que coincide la revisión bibliográfica con los expertos en las entrevistas realizadas, por lo cual se realizó la respectiva triangulación con os siguientes resultados:

\begin{tabular}{|c|c|c|}
\hline Indicador & Variable & Descripción \\
\hline \multirow{2}{*}{ Marca } & Logo & \multirow{2}{*}{$\begin{array}{l}\text { Tener una marca significa contar con una imagen, un } \\
\text { nombre, ofrecer nuevas experiencias (diferenciadoras). }\end{array}$} \\
\hline & Eslogan & \\
\hline \multirow{3}{*}{ Página web } & Manejo & \multirow{3}{*}{$\begin{array}{l}\text { Es indispensable tener un sitio web especialmente en } \\
\text { turismo, todo debe ser direccionado a esta. El } 93,7 \% \text { de } \\
\text { las empresas ecuatorianas la tienen. }\end{array}$} \\
\hline & Contenido & \\
\hline & Diseño & \\
\hline \multirow[b]{2}{*}{ Videomarketing } & Contenido & \multirow{2}{*}{$\begin{array}{l}\text { Debe ser vivencial, contar experiencias por medio de } \\
\text { usuarios (es muy usado ahora), corto, conciso } \\
\text { vendedor, viral, compartible, su duración recomendable } \\
\text { es } 30 \mathrm{~s} \text {. }\end{array}$} \\
\hline & Duración & \\
\hline \multirow[t]{2}{*}{$\begin{array}{l}\text { Inbound } \\
\text { Marketing }\end{array}$} & Estrategias & $\begin{array}{l}\text { Viene más de las agencias, se crea contenido de valor } \\
\text { (consejos o datos interesantes), no tiene tanta ventaja } \\
\text { por la competencia turística, además como recién se } \\
\text { empieza no hay muchas cosas diferenciadoras. }\end{array}$ \\
\hline & Esquema & \\
\hline
\end{tabular}




\begin{tabular}{|c|c|l|}
\hline \multirow{2}{*}{$\begin{array}{c}\text { Plan de } \\
\text { Promoción } \\
\text { digital }\end{array}$} & Estrategias & $\begin{array}{l}\text { Determinar a donde se quiere llegar, metas y objetivos } \\
\text { para alcanzarlas; conocer las bondades que se desean } \\
\text { promocionar; target, los usuarios a los que se quiere } \\
\text { llegar; determinar la competencia, ventajas, las } \\
\text { fortalezas; seleccionar los canales y medios; establecer } \\
\text { un presupuesto. Las estrategias recomendadas son: } \\
\text { administrar y contestar mensajes (tener un community } \\
\text { manager), hacer que las personas compartan sus fotos } \\
\text { en redes sociales convirtiéndose en agentes de viajes, } \\
\text { compartir fotos de algo icónico, de cosas diferentes. }\end{array}$ \\
\hline \multirow{2}{*}{$\begin{array}{c}\text { Pago a redes } \\
\text { sociales }\end{array}$} & Con quién & $\begin{array}{l}\text { Pág. web entre 1000 y 1500. A través de la pág. se } \\
\text { selecciona un módulo de pago (tarjeta de crédito), se } \\
\text { crean campañas dependiendo de los productos, se elige } \\
\text { el objetivo de la campaña, target, valor a invertir (desde } \\
\text { \$10). *Presupuesto interesante si se quieren resultados } \\
\text { interesantes. }\end{array}$ \\
\cline { 2 - 3 } & Cuánto \\
\hline
\end{tabular}

En la segunda fase se realizó el registro de los atractivos turísticos de la Comuna Dataposorja, mediante un levantamiento de información, implementada en fichas de registro donde se detalla el nombre del atractivo, la categoría a la q pertenece, el tipo y subtipo su ubicación y la descripción del mismo.

Con el levantamiento de esta información se determinaron que los principales recursos turísticos de esta comunidad está el Museo Matrona de los Vientos que lleva el nombre de su principal vestigio de la Cultura Manteño Huancavilca 1. El monumento del Delfín ubicado en la playa del mismo nombre. Las manifestaciones culturales también se presentan como recursos turísticos sus leyendas y oficios tradicionales como es la extracción de Ostras, y en recursos naturales podemos encontrar la Isla de los pájaros un centro de anidación y reproducción de aves con una colonia gigantesca de fragatas, piqueros patas azules, garzas, pelicanos, entre otros.

\section{Perfil de la demanda digital}

En la fase final metodológica según los resultados arrojados por las encuestas se determinó el perfil de la posible demanda digital de la Comuna Data de Posorja, posee las características detalladas a continuación:

- Millennials, cuya edad varía entre 24 a 36 años.

- De ambos sexos debido a la proximidad de porcentajes, $51,7 \%$ masculino y $48,3 \%$ femenino.

- Nacionales, específicamente habitantes de la ciudad de Guayaquil.

- Trabajadores, justificando la solvencia económica que implica viajar.

- Tienen como motivación principal la obtención de nuevas experiencias.

- Prefieren obtener información de un destino turístico a través de las redes sociales.

- El celular es el dispositivo que más utilizan para buscar información de interés turístico.

- Las actividades en la que implican el uso de su celular son la comunicación $(50,2 \%)$ y las redes sociales $(46,4 \%)$, siendo la más acogida Facebook. 
- Para obtener más información de una publicidad que les ha causado interés optan por visitar la página web $(33,7 \%)$, comentar la publicación $(32,6 \%)$ o escribir al whatsapp $(30,3 \%)$.

- Sus indicadores financieros son los siguientes: el 65,5\% posee cuenta bancaria, el $24 \%$ tarjeta de crédito, el 19,8\% realiza pagos móviles, el 9,7\% compra vía online y el 49,4\% recibe facturas electrónicas.

- Los fines de semana son considerados su momento predilecto para viajar.

\section{Discusión}

El plan de promoción digital tiene como fin Potenciar el turismo en la Comuna Data de Posorja implementando un plan de promoción digital. Mediante la Creación de una marca turística que identifique a la Comuna Data de Posorja como destino turístico. A través de estrategias competitivas de Marketing digital en el que muestra como el marketing digital, el cual es utilizado para las grandes industrias, puede ser una herramienta que puede contribuir a potenciar el Turismo Comunitario en zonas de bajo nivel de desarrollo mediante estrategias como las detalladas a continuación:

- La marca debe poseer un ícono representativo del destino que se desea promocionar y lo recomendable es solicitar los servicios de un diseñador gráfico para su elaboración debido a su conocimiento en colorimetría, estandarización, alguien que plasme lo que se desea reflejar.

- Los medios ideales para promocionar en el ámbito turístico son las redes sociales facebook e instagram debido a su gran acogida por los usuarios y porque permiten una mayor difusión de información, con un adecuado manejo de éstas se logrará posicionar a un sitio y que el uso de una página web su creación es fundamental para las estrategia digitales.

- El story telling a través de videomarketing con una duración entre 30 segundos a dos minutos en el que se relate experiencias que inciten una visita, a compartir el contenido y hacerlo viral.

- Las mejores estrategias serían realizar concursos ofreciendo premios llamativos que inciten a seguir las cuentas, compartir experiencias, fotos únicas y contenido de valor como consejos o datos interesantes.

- Un plan de promoción digital debería contener metas y objetivos, un producto y público establecido, canales y medios a utilizar, ventajas, fortalezas, competencia y un presupuesto, concordando con Tomalá Reyes.

\section{Conclusiones.}

Las estrategias de promoción evolucionan constantemente, y la tendencia actual es la utilización de los medios digitales que si bien es cierto en el turismo las empresas y destinos lo consideran en sus promociones, en las comunidades rurales donde se aplica el Turismo Comunitario aún es muy deficiente este tipo de estrategias. 

representativos de la comuna, los mismos que forman parte de la identidad cultural que caracteriza a este destino.

$>$ Las redes sociales utilizadas: facebook e instagram, fomentarán la interacción entre usuarios y el destino (a través de su administrador); a su vez se dará a conocer como destino turístico a su perfil de demanda digital generando interés a través de las publicaciones y recomendaciones que se ofrezcan en las páginas.

$>$ Una adecuada promoción de la oferta turística de la Comuna Data de Posorja dará como resultado el incremento del número de visitas a este destino permitiendo un mejor desarrollo socioeconómico a sus habitantes.

\section{Referencias Bibliográficas.}

[1] Kotler Philip. Marketing Turístico 5ta edicion . Madrid . 2012 . Editorial Pearson Educacion. ISBN 978-84-8322-808-1

[2] PIEDRA Nelson, CHICAIZA Janeth, QUICHIMBO Priscila. Marco de trabajo para la integración de recursos digitales basado en un enfoque de web semántica. REVITA IBÉRICA de Sistemas y Tecnología de Información. Nro E3. 03/2015; pag $55-70$

[3] PANIAGUA Francisco, HUERTAS Assumpció. El contenido en los medios sociales de los destinos turísticos y la búsqueda de información de los usuarios. Revista Cuadernos de Turismo. Nro 41 (2018) pp 513 - 534. Disponible en http://dx.doi.org/10.6018/turismo.41.327131. ISSN: 1139- 7861.

[4] LAGE Agustín. La Economía del Conocimiento y El Socialismo Segunda Edición. 2015 La Habana. Sello Editorial Academia. ISBN 978 - 959-270-329-2.

[5] ALVAREZ SOUZA Antonio. Imagen, Lealtad y Promoción Turística. Análisis con ecuaciones estructurales. Revista Pasos Vol.13 2015 No3 Pags629 -648 ISSN $1695-7121$

[6] GOMEZ Andreina. Influencers para la promoción de destinos turísticos. Revista marketing Visionario. Volumen 6 Edición No 2 Noviembre 2017 - Abril 2018. Disponible . Issn: 2343-5771

[7] PIÑEIRO NAVAL Valeriano, SERRA Paulo, MANGANA Rafael. Desarrollo local y turismo El impacto Socioeconómico de la Comunicación Digital en Portugal. Revista Latina de Comunicación Social, V 72, 2017, pp 1515 a 1535. Disponible en http://www.revistalatinacs.org/072paper/1232/82es.html. ISSN 1138-5820

[8] SASTRE Jhon. Plan Estratégico de Turismo de la Comunitat Valenciana 2010-2020 Valencia España 2012 
[9] ANDRADE YEJAS David Albeiro. Estrategias de Marketing digital en la promoción de una ciudad. Revista Escuela Administración Negocios. Nro 80. Enero - Junio, 2018. Pp 59- 72. Disponible en ISSN 1695 - 7121

[10] CHAVEZ GARCIA Elsita, ALARCON Gina, HARO Giovanny, ALBARRASIN Marilin. Sistema de Gestión de marketing Digital para el Desarrollo Turístico del Cantón Caluma, Provincia Bolívar Ecuador. Revista de Investigación Talentos IV(2) 23- 322017 ISSN $1280-6325$

[11] VERGARA ZURITA Heidy Elizabeth, PALACIOS TRUJILLO Edinson, ESCUDERO VILLA Amalia. Desarrollo de los Atractivos Turísticos del Cantón Penipe con Estrategias de Marketing Digital. Revista Mkt Descubre No 9 Junio 2017 , Pp 125- 133 .ISSN 1390 - 7352

[12] RODRIGUEZ Cesar. E Tourism Applyng Geolocation Techonology, virtual tours and augmented reallity mobile. Published IEEE Thirty Central American and Panama Convention (CONCAPAN XXXV) 11- 13 Nov 2015 . Panamá . Inspec Accession Number 15838569

[13] ALBAN ALENCASTRO Juan, BETANCOURT Valeria, CAHUEÑAS MUÑOZ Hugo. Derechos digitales. Quito 2016. Editorial USQF. ISBN 978-9978-68-0971

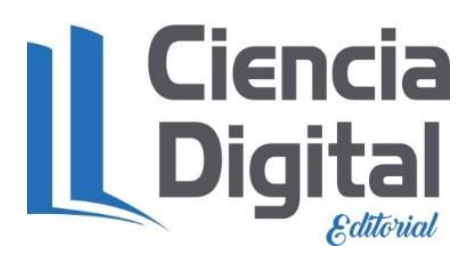




\section{Para citar el artículo indexado.}

Guillén S., Quinde L., Vera V. \& Hasing L. (2019) Promoción digital para potenciar el turismo en la comuna data de Posorja, Ecuador. Revista electrónica Explorador Digital 3(3), 5-14. Recuperado desde:

http://cienciadigital.org/revistacienciadigital2/index.php/exploradordigital/article/view/439/9 87

\section{Ciencia \\ Digital \\ Editorial}

El artículo que se publica es de exclusiva responsabilidad de los autores y no necesariamente reflejan el pensamiento de la Revista Explorador Digital.

El articulo queda en propiedad de la revista y, por tanto, su publicación parcial y/o total en otro medio tiene que ser autorizado por el director o editor de la Revista Explorador Digital.
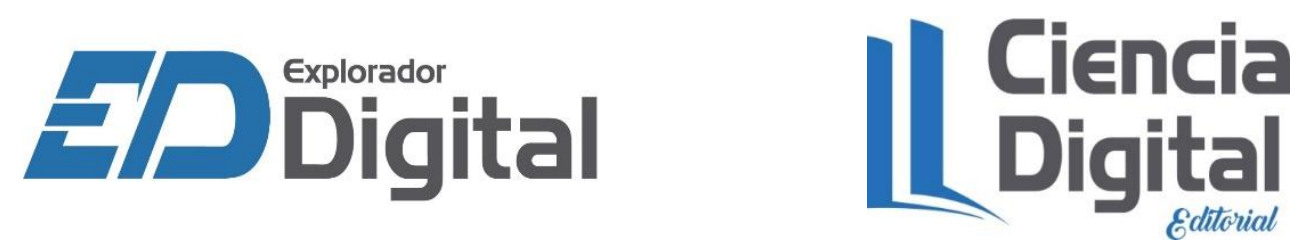